\title{
Apoptosis-inducing effect of the DR5 monoclonal antibody, D-6, alone or in combination with cisplatin, on A2780 ovarian cancer cells
}

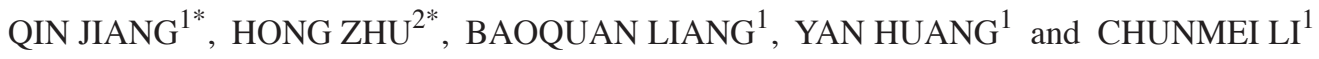 \\ ${ }^{1}$ Department of Obstetrics and Gynecology, West China Second University Hospital; ${ }^{2}$ Department of Abdominal Cancer, \\ West China Hospital, Sichuan University, Chengdu, Sichuan 610041, P.R. China
}

Received February 26, 2012; Accepted April 26, 2012

DOI: $10.3892 / \mathrm{mmr} .2012 .902$

\begin{abstract}
Death receptor 5 (DR5) antibody (D-6) is a monoclonal antibody directed against DR5. The aim of this study was to explore the apoptosis-inducing effects of DR5 (D-6), alone or in combination with cisplatin, on A2780 ovarian cancer cells. The cells were treated with various concentrations of cisplatin and/ or DR5 (D-6), or a combination of both. For the control group, the cells were treated only with culture medium. Twenty-four hours after the culture, the morphological changes of each group were observed under an inverted microscope. The cell growth inhibition rates were also analyzed by 3-(4,5-dimethylthiazol2-yl)-2,5-diphenyltetrazolium bromide (MTT) assays, and the apoptosis was analyzed by flow cytometry. Western blotting analysis was used to detect the intracellular reaction. Our results showed that DR5 monoclonal antibody (D-6) was able to induce the apoptosis and increase the cell growth inhibition rates of ovarian cancer cells in a dose-dependent manner, and the effect was enhanced by cisplatin. There were significant morphological changes, a higher cell growth inhibition rate and apoptosis rate and lesser expression of caspase-3, 8, 9 precursors in the cells treated with both cisplatin and DR5 (D-6). The combination treatment of the DR5 monoclonal antibody (D-6) with cisplatin may be a promising treatment for ovarian cancer.
\end{abstract}

Correspondence to: Dr Chunmei Li, Department of Obstetrics and Gynecology, West China Second University Hospital, Sichuan University, 20 People's South Road, Chengdu, Sichuan 610041, P.R. China

E-mail: 1cmwch@126.com

*Contributed equally

Abbreviations: DR5 (D-6), monoclonal antibody (D-6) against death receptor 5; OD, optical density; DD, death domain; TRAIL, TNF-related apoptosis-inducing ligand;MTT,3-(4,5-dimethylthiazol2-yl)-2,5-diphenyltetrazoliumbromide;EDTA, ethylenediaminetetraacetic acid; DISC, death-inducing signaling complex

Key words: monoclonal antibody (D-6) against death receptor 5, cisplatin, ovarian cancer cell, apoptosis, TNF-related apoptosisinducing ligand

\section{Introduction}

As one of the most lethal gynecological cancers, ovarian cancer is the fifth leading cause of cancer-related mortality among women in Western countries. Most ovarian cancer cells originate from the ovarian surface epithelium and display a range of histological subtypes (1). Platinum is the first-line drug for the chemotherapy of ovarian cancer (2).

The TNF-related apoptosis-inducing ligand (TRAIL) is a TNF family member capable of inducing apoptosis through caspase-dependent mechanisms (3-6). TRAIL binds four major different receptors, two of which, death receptor (DR)4 and DR5, induce apoptosis; however, the other two, decoy receptor (DcR)1 and DcR2, do not have the intracytoplasmic death domain to transduce apoptotic death signals and, thus, they protect cells from TRAIL-mediated cell death by interfering with signaling through DR4 and DR5 $(7,8)$. Another receptor, osteoprotegerin (OPG), is a soluble receptor that may play a more prominent role in bone and myeloid cell development (9). In tumor cells, the expression of DR5 which is rare or even absent in healthy cells predominates over that of DR4; therefore, DR5 plays a major role in TRAIL-induced apoptosis $(4,10)$. In order to find an alternative for TRAIL for clinical treatment, monoclonal antibodies inducing the apoptosis of tumor cells via targeting DR5 have been developed, such as TRA-8, Apomab and CS-1008 (2,12-14).

The DR5 monoclonal antibody (D-6) is a type of murine monoclonal antibody directed againts DR5, produced by Santa Cruz Biotechnology Co. In this study, we explored the apoptosis-inducing effects of the DR5 monoclonal antibody (D-6), alone or in combination with the platinum-based drug, cisplatin, on the A2780 ovarian cancer cell line.

\section{Materials and methods}

Cell culture and reagents. All animal procedures were approved by the Animal Care and Scientific Committee of Sichuan University, Chengdu China. The A2780 cells were kindly provided by Kanghong Co. (Chengdu, China). The DR5 monoclonal antibody (D-6) was purchased from Santa Cruz Biotechnology Co. (Santa Cruz, CA, USA). Cisplatin was purchased from the West China Second Hospital, Sichuan 
University. The RPMI-1640 culture medium, dimethylsulfoxide (DMSO) and fetal bovine serum were purchased from Gibco (Carslbad, CA, USA). The 3-(4,5-dimethylthiazol-2-yl)-2,5diphenyltetrazolium bromide (MTT) cell proliferation assay kit and trypsin were purchased from Sigma (Sigma, St. Louis, USA). The Annexin V-FITC apoptosis detection kit and protein extraction kit were purchased from KeyGen Biotech Co. (Nanjing, China). The BCA protein assay kit, SDS-PAGE protein sample buffer (5X), SDS-PAGE gel preparation kit and the BeyECL Plus chemiluminescence kit were purchased from Beyotime Co. (Jiangsu, China). The caspase 3,8 and 9 precursor antibodies were purchased from Santa Cruz Biotechnology Co. Polyvinylidene difluoride (PVDF) membranes were purchased from Millipore (Billerica, MA, USA). The enhanced chemiluminescence (ECL) detection kit and X-ray films were purchased from Roche (Basel, Switzerland).

Apoptosis observation under a microscope. The A2780 cells were counted and cultured in 6-well plates at a concentration of $2 \times 10^{5}$ cells/well. they were then divided into four groups: the control group, where $2 \mathrm{ml}$ culture medium was added to the wells; the cisplatin group, where $2 \mathrm{ml}$ culture medium containing $2.5 \mu \mathrm{g} / \mathrm{ml}$ cisplatin was added; the DR5 (D-6) group, where $2 \mathrm{ml}$ culture medium containing $2 \mu \mathrm{g} / \mathrm{ml}$ DR5 (D-6) was added; and the combination group, where $2 \mathrm{ml}$ culture medium containing $2.5 \mu \mathrm{g} / \mathrm{ml}$ cisplatin and $2 \mu \mathrm{g} / \mathrm{ml}$ DR5 (D-6) was added. Twentyfour hours after the culture, the morphological changes of each group were observed under an inverted microscope.

MTT analysis. The A2780 ovarian cancer cells were first counted and incubated in two 96-well plates at a concentration of $5 \times 10^{3}$ cells/well and a volume of $0.1 \mathrm{ml} /$ well in 30 wells of each plate. After culture in the RPMI-1640 culture medium containing $10 \%$ fetal bovine serum, the 30 wells of one plate were randomized into six groups (five wells/group) and $0.1 \mathrm{ml}$ culture medium containing $0,0.125,0.25,0.5,1$ and $2 \mu \mathrm{g} / \mathrm{ml}$ DR5 (D-6) was added, after drying out the supernatant. The other plate was also divided into six groups (five wells/group) and $0.1 \mathrm{ml}$ culture medium containing $2.5 \mu \mathrm{g} / \mathrm{ml}$ cisplatin and $0.125,0.25,0.5,1$ and $2 \mu \mathrm{g} / \mathrm{ml}$ DR5 (D-6) was added, after drying out the supernatant, except for one group (the contol) in which $0.1 \mathrm{ml}$ culture medium was added. After $48 \mathrm{~h}$ of culture in the incubator, $10 \mu \mathrm{l}$ MTT was added to each well. The plates were then incubated at $37^{\circ} \mathrm{C}$ for an additional $4 \mathrm{~h}$ to allow MTT to form formazan crystals by reacting with metabolically active cells. The formazan crystals were solubilized in $0.1 \mathrm{ml} \mathrm{DMSO}$ per well at $37^{\circ} \mathrm{C}$ for $10 \mathrm{~min}$. The absorbance values of the solution in each well were measured at $450 \mathrm{~nm}$ using a multiscanner autoreader. The cell growth inhibition rate was calculated as follows: [1 - (OD test - OD blank)/(OD control - OD blank) x100\% (11).

Flow cytometry. The A2780 ovarian cancer cells were counted and cultured in four wells of a six-well plate at a concentration of $2 \times 10^{5}$ cells/well and a volume of $2 \mathrm{ml} /$ well. After culture in the incubator for $24 \mathrm{~h}$, the supernatant was dried out and the four wells were randomized into four groups: the control group, where $2 \mathrm{ml}$ culture medium was added; the DR5 (D-6) group, where $2 \mathrm{ml}$ culture medium containing $1 \mu \mathrm{g} / \mathrm{ml}$ DR5 (D-6) was added; the cisplatin group, where $2 \mathrm{ml}$ culture medium containing $2.5 \mu \mathrm{g} / \mathrm{ml}$ cisplatin was added; and the combination group, where $2 \mathrm{ml}$ culture medium containing $1 \mu \mathrm{g} / \mathrm{ml}$ DR5 (D-6) and $2.5 \mu \mathrm{g} / \mathrm{ml}$ cisplatin was added. After $24 \mathrm{~h}$ in the incubator, the cells were digested with EDTA-free trypsin and washed twice with PBS. For each group, 1-5x10 cells were collected. The cells were then suspended in binding buffer $(500 \mu \mathrm{l})$, and then $5 \mu \mathrm{l}$ Annexin V-FITC and $5 \mu \mathrm{l}$ PI were added. After $10 \mathrm{~min}$ of reaction in a dark environment, the cell apoptotic rate was evaluated by flow cytometry.

Western blot analysis. The A2780 ovarian cancer cells were counted and cultured in the four culture dishes at a concentration of $10^{6}$ cells/well and a volume of $5 \mathrm{ml} /$ well. After culture in the incubator for $24 \mathrm{~h}$, the supernatant was dried out and the four wells were randomized into four groups: the control group, where $5 \mathrm{ml}$ culture medium was added; the DR5 (D-6) group, where $5 \mathrm{ml}$ culture medium containing $2 \mu \mathrm{g} / \mathrm{ml}$ DR5 (D-6) was added; the cisplatin group, where $5 \mathrm{ml}$ culture medium containing $2.5 \mu \mathrm{g} / \mathrm{ml}$ cisplatin was added; and the combination group, where $5 \mathrm{ml}$ culture medium containing $2 \mu \mathrm{g} / \mathrm{ml}$ DR5 (D-6) and $2.5 \mu \mathrm{g} / \mathrm{ml}$ cisplatin was added. After $48 \mathrm{~h}$ in the incubator, the cells from each group were collected and protein extraction was carried out using the protein extraction kit. Protein $(35 \mu \mathrm{g})$ extracted from the cells of each group was subjected to SDS-PAGE electrophoresis and then the gel was electroblotted on a PVDF membrane for $60 \mathrm{~min}$. The membrane was incubated with 5\% non-fat dry milk in TBS for $1 \mathrm{~h}$ to block non-specific binding sites, and then incubated with the appropriate primary antibody concentration (1:200 dilution for caspase 3, 8 and 9 precursors) overnight. The membrane was subsequently rinsed in TBS-T and incubated for $1 \mathrm{~h}$ at $37^{\circ} \mathrm{C}$ with secondary antibody. After incubation, the membrane was finally rinsed and visualized with ECL detection reagents.

Statistical analysis. The cell growth inhibition rate and apoptotic rate were analyzed by one-way ANOVA and the Student's t-test. All statistical analyses were performed using the SPSS 17.0 software package. All $\mathrm{P}$-values were two-sided and $\mathrm{P}<0.05$ was considered to indicate a statistically significant difference.

\section{Results}

Morphological changes observed under a microscope. As shown in Fig. 1, $24 \mathrm{~h}$ after the treatment, the cells of both the DR5 (D-6) and cisplatin groups showed evident apoptosis; these effects were more evident in the DR5 (D-6) and cisplatin combination group. In the combination group, there were many floating cells and only a few cells grew along the wall. The cells underwent significant changes in morphology; their original shape was completely altered, the cytoplasm became rougher, the nucleus became pycnotic and the refractive index in the cells decreased, demonstrating significant cellular damages. By contrast, A2780 cells in the control group did not demonstrate significant morphological changes.

Cell growth inhibition rate. The cell growth inhibition rates were analyzed by MTT assays. As shown in Fig. 2, the cell growth inhibition rates increased following the increasing DR5 (D-6) concentrations $>0.25 \mu \mathrm{g} / \mathrm{ml}(\mathrm{P}<0.05)$ in both groups, and in the DR5 (D-6) and cisplatin combination group these rates 


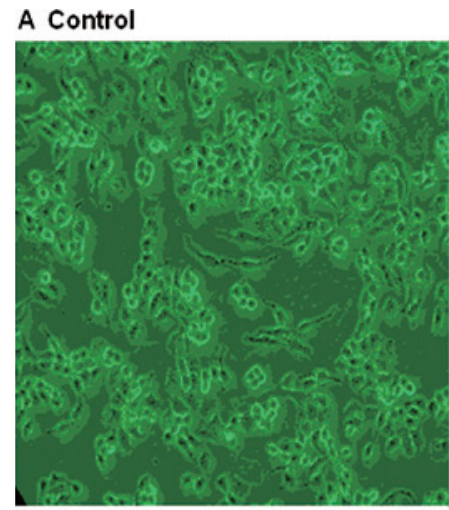

B Cisplatin

\section{DR5 (D-6)}

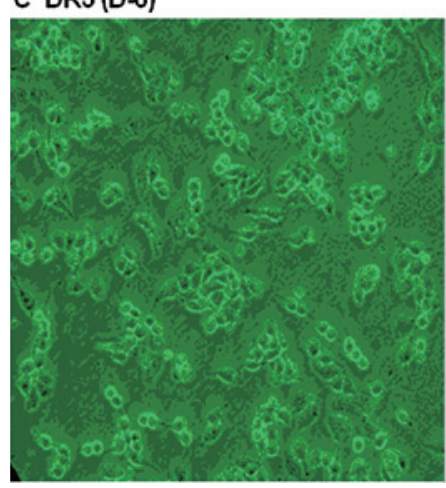

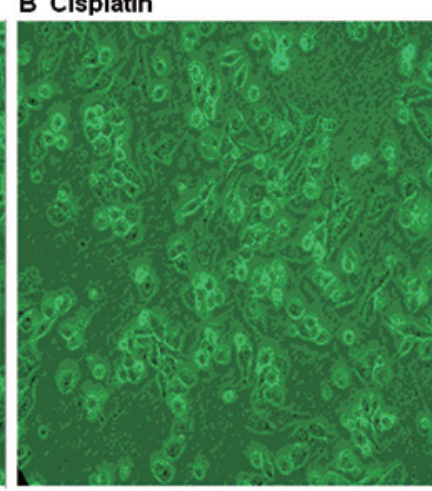

D Cisplatin and DR5 (D-6)

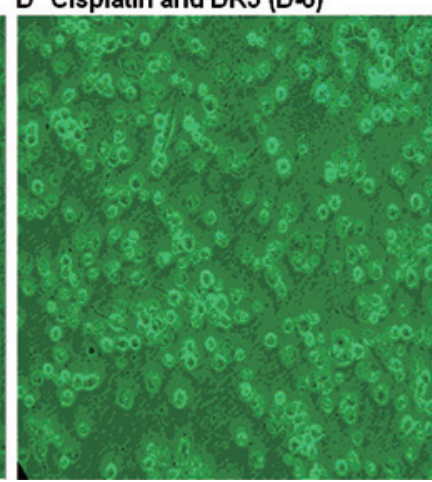

A Control

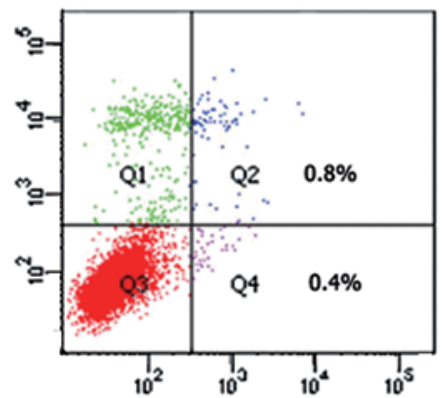

C DR5 (D-6)

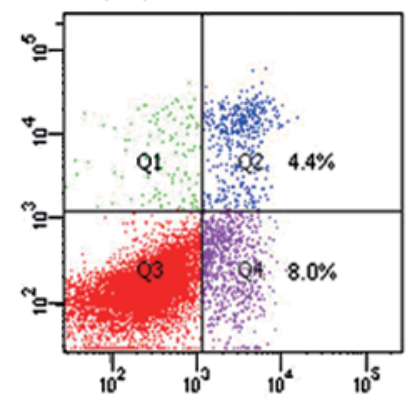

B Cisplatin

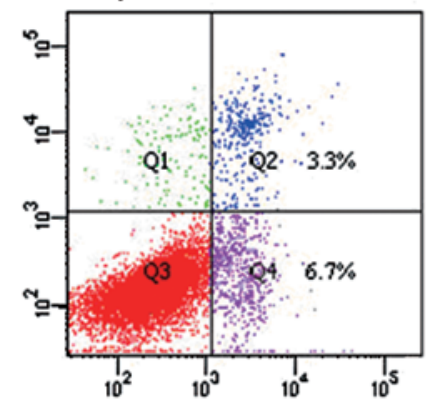

D DR5 (D-6) + Cisplatin

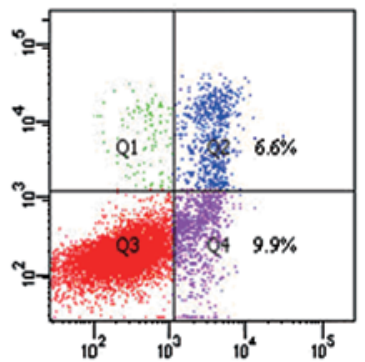

Figure 3. Apoptotic rate of the A2780 ovarian cancer cells analyzed by flow cytometry after treatment. (A) Control group; (B) cisplatin group; (C) DR5 (D-6) group; (D) DR5 (D-6) combined with cisplatin group.

\section{Combined Cisplatin DR5 (D-6) Control}

Caspase 3 precursor

Figure 4. Western blot analysis of caspase 3 precursor after treatment (A) Control group, treated with $5 \mathrm{ml}$ culture medium. (B) DR5 (D-6) group, treated with $5 \mathrm{ml}$ culture medium containing $2 \mu \mathrm{g} / \mathrm{ml}$ DR5 (D-6). (C) Cisplatin group, treated with $5 \mathrm{ml}$ culture medium containing $2.5 \mu \mathrm{g} / \mathrm{ml}$ cisplatin. (D) Combined group, treated with $5 \mathrm{ml}$ culture medium containing $2 \mu \mathrm{g} / \mathrm{ml}$ DR5 (D-6) and $2.5 \mu \mathrm{g} / \mathrm{ml}$ cisplatin.

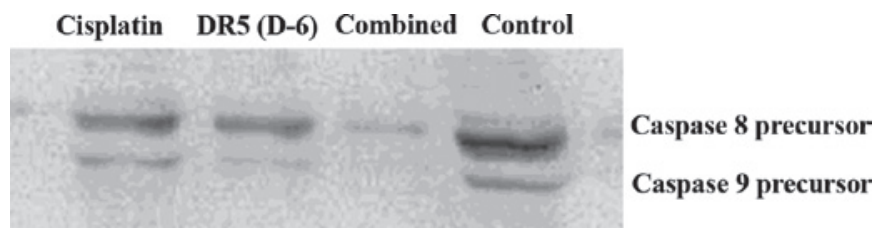

Figure 5. Western blot analysis of caspase 8 and 9 precursors after treatment. (A) Control group, treated with $5 \mathrm{ml}$ culture medium. (B) DR5 (D-6) group, treated with $5 \mathrm{ml}$ culture medium containing $2 \mu \mathrm{g} / \mathrm{ml}$ DR5 (D-6). (C) Cisplatin group, treated with $5 \mathrm{ml}$ culture medium containing $2.5 \mu \mathrm{g} / \mathrm{ml}$ cisplatin. (D) Combined group, treated with $5 \mathrm{ml}$ culture medium containing $2 \mu \mathrm{g} / \mathrm{ml}$ DR5 (D-6) and $2.5 \mu \mathrm{g} / \mathrm{ml}$ cisplatin.

the control, DR5 (D-6), cisplatin and combination groups, respectively (Fig. 3). The apoptotic rate of the DR5 (D-6) and cisplatin combination group was significantly higher than that of the other three groups $(\mathrm{P}<0.05)$; it was higher in the DR5 (D-6) and cisplatin groups than in the control group $(\mathrm{P}<0.05)$. However, there was no significant difference between the DR5 (D-6) group and the cisplatin group $(\mathrm{P}>0.05)$.

Western blot analysis of intracellular protein changes. As shown in Figs. 4 and 5, $48 \mathrm{~h}$ after treatment, the caspase 3, 8 
and 9 precursors decreased in the DR5 (D-6), cisplatin and DR5 (D-6) and cisplatin combination groups compared to the control group; this decrease was more significant in the combination group.

\section{Discussion}

Various cancer therapies using TRAIL-induce apoptosis have been developed over the past few years, and many DR5 monoclonal antibodies, including murine or humanized, have been produced, such as TRA-8, Apomab and CS-1008 (2,12-14). The DR5 monoclonal antibodies have been used to a greater extent than TRAIL, since they have a longer half-life in the circulatory system and have been shown to have significant anti-tumor effects $(7,15,16)$.

A number of studies have focused on the mechanism of TRAIL-induced apoptosis, and it is generally accepted that the caspase-dependent pathway is involved $(5,6,10)$. Upon the binding of TRAIL to either DR4 or DR5 on the cell membrane, DR4 and DR5 promote the formation of the death-inducing signaling complex (DISC) via the intracellular death domain (DD), recruiting certain adaptor proteins (5). After the formation of DISC, caspase 8 and 10 are recruited to DISC, and are activated automatically by protein hydration and, thereafter, downstream effectors, such as caspase 3,6 and 7 are activated, through a series of cascade reactions to trigger biological reactions of apoptosis (13). Exposure to chemotherapy may stimulate the intrinsic pathway which causes the destabilization of the mitochondrial membrane with the release of cytochrome c, leading to caspase 3 activation. During the cascade reaction, caspase 9 has also been shown to be highly activated $(6,17)$.

In this study, we show that DR5 (D-6), a novel DR5 monoclonal antibody, is effective in inducing apoptosis of the A2780 ovarian cancer cell line. The combination of DR5 (D-6) and cisplatin was even more effective. In the experiment under the inverted microscope, although both the DR5 (D-6) and cisplatin groups showed apoptosis-inducing effects, the effects in the combination group were more significant. In the combination group, most of the cells were changed into roundshaped and floated on the surface. Therefore, we hypthesize that they had a synergistic function in inducing apoptosis.

The results of MTT revealed that the A2780 ovarian cancer cells were sensitive to DR5 (D-6) in a dose-dependent manner, and this effect was enhanced by cisplatin. A number of studies have investigated the effect of other DR5 monoclonal antibodies on other tumor cells in combination with chemotherapy or radiotherapy (18-21). It is thought that chemotherapy sensitizes the apoptosis-inducing effect of the DR5 monoclonal antibody $(20,22)$. A number of studies have provided evidence of a correlation between cisplatin and DR5 monoclonal antibodies. Chemotherapy not only sensitizes the target cells to the DR5 monoclonal antibody, but DR5 monoclonal antibody may also enhance the effects of chemotherapy $(14,22)$. This is very important for the platinum-resistant types of cancer, such as ovarian cancer. Most ovarian cancers are sensitive to platinum-based chemotherapy at the time of diagnosis; however, recurrence of the disease is frequent and, ultimately, platinum-resistant disease develops in all patients (1). Thus, the DR5 monoclonal antibody may play a role in the treatment of ovarian caner. In this study, we found that the A2780 ovarian cancer cell line did not undergo apoptosis under the concentration of $0.25 \mu \mathrm{g} / \mathrm{ml}$. This phenomenon occurred after many repeated examinations. The reason is unknown and requires further study.

The results of flow cytometry showed that the treatment of the A2780 ovarian cancer cells with DR5 (D-6), cisplatin or the combination of both produced apoptosis-inducing effects; these effects were more significant in the combination group. In order to observe the internal reaction of the ovarian cells after treatment, we examined the expression of caspase 3, 8 and 9 precursors, which are usually used as reaction proteins of apoptotic pathways (8). Western blot analysis showed that the caspase 3,8 and 9 precursors decreased evidently in the treatment group. Therefore, we believe that the apoptosis of the ovarian cancer cells in this study occured in a caspasedependent manner.

In conclusion, the monoclonal antibody (D-6) directed against DR5 was capable of inducing the apoptosis of ovarian cancer cells in a dose-dependent manner, and this effect was enhanced by cisplatin. The combined treatment of cells with the DR5 monoclonal antibody and cisplatin may be a promising treatment for ovarian cancer.

\section{Acknowledgements}

This study was supported by grants from the National Natural Scientific Foundation of China (no. 30973192).

\section{References}

1. Bevis KS, McNally LR, Sellers JC, Della Manna D, Londono Joshi A, Amm H, Straughn JM Jr and Buchsbaum DJ: Anti-tumor activity of an anti-DR 5 monoclonal antibody, TRA-8, in combination with taxane/platinum-based chemotherapy in an ovarian cancer model. Gynecol Oncol 121: 193-199, 2011.

2. Estes JM, Oliver PG, Straughn JM Jr, Zhou T, Wang W, Grizzle WE, Alvarez RD, Stockard CR, LoBuglio AF and Buchsbaum DJ: Efficacy of anti-death receptor 5 (DR5) antibody (TRA-8) against primary human ovarian carcinoma using a novel ex vivo tissue slice model. Gynecol Oncol 105: 291-298, 2007.

3. Buchsbaum DJ, Forero-Torres A and LoBuglio AF: TRAILreceptor antibodies as a potential cancer treatment. Future Oncol 3: 405-409, 2007

4. Du YW, Chen JG, Bai HL, Huang HY, Wang J, Li SL, Liu GC, Jiang Q, Chai J, Zhao YP and Ma YF: A novel agonistic antihuman death receptor 5 monoclonal antibody with tumoricidal activity induces caspase- and mitochondrial-dependent apoptosis in human leukemia Jurkat cells. Cancer Biother Radiopharm 26: 143-152, 2011.

5. Du YW, Liu GC, Wang J, Zhao YP, Li SL, Chen JG, Jiang Q, Cai J and Ma YF: Caspase-dependent molecular mechanisms of anti-human DR5 monoclonal antibody mDRA-6 inducing apoptosis of human leukemia Jurkat cells. Ai Zheng 28: 112-116, 2009.

6. Wu XX and Kakehi Y: Enhancement of lexatumumab-induced apoptosis in human solid cancer cells by Cisplatin in caspasedependent manner. Clin Cancer Res 15: 2039-2047, 2009.

7. Wang J, Lin Z, Qiao CX, Lv M, Yu M, Xiao H, Wang Q, Wang L, Feng J, Shen B, Ma Y and Li Y: Characterization of a novel anti-DR 5 monoclonal antibody WD1 with the potential to induce tumor cell apoptosis. Cell Mol Immunol 5: 55-60, 2008.

8. Wang YG, Zhao KP, Chen JG, Zhang JY, Yu M, Li Y and Shen BF: The characteristic of an anti-human DR5 antibody A6. Cell Mol Immunol 5: 183-188, 2008.

9. Yagita H, Takeda K, Hayakawa Y, Smyth MJ and Okumura K: TRAIL and its receptors as targets for cancer therapy. Cancer Sci 95: 777-783, 2004.

10. Guo Y, Chen C, Zheng Y, Zhang J, Tao X, Liu S, Zheng D and Liu Y: A novel anti-human DR5 monoclonal antibody with tumoricidal activity induces caspase-dependent and caspaseindependent cell death. J Biol Chem 280: 41940-41952, 2005. 
11. Li W, Wang S, Chen C and Zhuang G: Induction of tumor cell apoptosis via Fas/DR5. Cell Mol Immunol 3: 467-471, 2006.

12. Kang Z, Chen JJ, Yu Y, Li B, Sun SY, Zhang B and Cao L: Drozitumab, a human antibody to death receptor 5 , has potent antitumor activity against rhabdomyosarcoma with the expression of caspase-8 predictive of response. Clin Cancer Res 17: 3181-3192, 2011.

13. Yada A, Yazawa M, Ishida S, Yoshida H, Ichikawa K, Kurakata S and Fujiwara K: A novel humanized anti-human death receptor 5 antibody CS-1008 induces apoptosis in tumor cells without toxicity in hepatocytes. Ann Oncol 19: 1060-1067, 2008.

14. Jin H, Yang R, Ross J, Fong S, Carano R, Totpal K, Lawrence D, Zheng Z, Koeppen H, Stern H, Schwall R and Ashkenazi A: Cooperation of the agonistic DR5 antibody apomab with chemotherapy to inhibit orthotopic lung tumor growth and improve survival. Clin Cancer Res 14: 7733-7740, 2008.

15. Duiker EW, Mom CH, de Jong S, Willemse PH, Gietema JA, van der Zee AG and de Vries EG: The clinical trail of TRAIL. Eur J Cancer 42: 2233-2240, 2006.

16. Camidge DR: Apomab: an agonist monoclonal antibody directed against Death Receptor 5/TRAIL-Receptor 2 for use in the treatment of solid tumors. Expert Opin Biol Ther 8: 1167-1176, 2008.

17. Liu YJ, Ma YF, Zhang J, Zhao YP, Bai HL and Li SL: Synergistic lethal effect of mDRA-6 and nimesulide on human hepatocellular cancer cell line SMMC-7721. Ai Zheng 27: 374-378, 2008.
18. Li SL, Ma YF, Liu GC, Zhang J, Bai HL, Liu YJ and Lu F: Adriamycin enhances anti-human DR5 monoclonal antibody (mDRA-6) induced HL-60 cells apoptosis. Zhonghua Xue Ye Xue Za Zhi 27: 461-464, 2006.

19. Ding B, Wu X, Fan W, Wu Z, Gao J, Zhang W, Ma L, Xiang W, Zhu Q, Liu J, Ding X and Gao S: Anti-DR5 monoclonal antibody-mediated DTIC-loaded nanoparticles combining chemotherapy and immunotherapy for malignant melanoma: target formulation development and in vitro anticancer activity. Int J Nanomedicine 6: 1991-2005, 2011.

20. Kendrick JE, Straughn JM Jr, Oliver PG, Wang W, Nan L, Grizzle WE, Stockard CR, Alvarez RD and Buchsbaum DJ: Anti-tumor activity of the TRA-8 anti-DR5 antibody in combination with cisplatin in an ex vivo human cervical cancer model. Gynecol Oncol 108: 591-597, 2008.

21. Straughn JM Jr, Oliver PG, Zhou T, Wang W, Alvarez RD, Grizzle WE and Buchsbaum DJ: Anti-tumor activity of TRA-8 anti-death receptor 5 (DR5) monoclonal antibody in combination with chemotherapy and radiation therapy in a cervical cancer model. Gynecol Oncol 101: 46-54, 2006.

22. Rajeshkumar NV, Rasheed ZA, Garcia-Garcia E, Lopez-Rios F, Fujiwara K, Matsui WH and Hidalgo M: A combination of DR5 agonistic monoclonal antibody with gemcitabine targets pancreatic cancer stem cells and results in long-term disease control in human pancreatic cancer model. Mol Cancer Ther 9: 2582-2592, 2010. 